\title{
In memory of Professor Jerzy Dymecki (27.04.1926 - 31.08.2020)
}

\begin{abstract}
Professor Jerzy Marian Dymecki was born on 27 April 1926 in Warsaw. On 1 September 1939, after the outbreak of World War II, he began the life of a wanderer. He survived the occupation with his family in Sanok. There he worked in a railway car factory, attended clandestine classes completing elementary and lower secondary education (gymnasium), being simultaneously an active scout. After the end
\end{abstract} of the war, the family moved to Gdynia where his father (Jan Lech Dymecki 1902-1968) was employed at the Repair Shipyard and received an apartment. There, Jerzy Dymecki completed his education in high school and in September 1946 he became a student of the Medical Academy in Gdańsk, now called Medical University of Gdańsk. He was taking anatomy lessons in a relatively little-damaged Anatomicum building. The lecturer of anatomy was, like most lecturers of the Medical Academy of Gdańsk, a former employee of the Vilnius University, prof. Michat Reicher (1888-1972), author of the last volume of Human Anatomy entitled "Central Nervous System". Professor Dymecki recalled many wonderful lecturers he met during his studies (1946-1952): including prof. Tadeusz Bilikiewicz, who used to bring his patients to lectures and prof. Irena Konopacka-Semadeni, who was a soldier of the Home Army and a participant of the Warsaw Uprising. Professor's future wife, Nina (Janina Bem-Dymecka 19281993) was a co-worker (as a liaison officer) of prof. I. Konopacka-Semadeni. Before obtaining his diploma, he was offered a job at the Provincial Mental Health Clinic in Gdańsk. After graduating in 1952, hesitating about the choice of the specialty, he took a post at the Psychiatric Clinic of the Medical University of Gdańsk and a part-time job at the department of neurology of the municipal hospital in Gdynia. But in the autumn of 1955, the Ministry of Health offered him a job at the Psychoneurological Institute in Tworki, in the Department of Organization and
Health Protection. He changed his professional plans after a four-month course on the basics of neurology conducted by prof. Ewa Osetowska (1919-1978), who was fascinated by neuropathology after her stay in Belgium with prof. Ludo van Bogaert, an outstanding neuropathologist. Professor Jerzy Dymecki remained faithful to his neuropathological passion throughout his life. He asked to be employed in the Nervous System Histology Laboratory and in the neurological department where he studied neurology, as the specialty in neuropathology did not exist in Poland yet. He obtained the first degree of specialty in neurology in 1957 and the second degree of specialty in 1960. He obtained his PhD degree (1963) and habilitation (1969) under the supervision of prof. Ewa Osetowska, who planned to open a new specialty (neuropathology) and founded the Association of Neuropathologists in Poland. In 1963 he participated in the establishment of the Association of Polish Neuropathologists, and in 1974 he specialized in the field of neuropathology. At the beginning, the Laboratory was supervised by the head of the neurology department, doc. Ewa Osetowska, who initiated the archiving of diagnostic neuropathological material according to European standards. Doc. Maria Filipowicz was the first head of the Laboratory (1955-1963). When she left the post to become the head of the neurological ward at the Czerniakowski hospital doc. Jerzy Dymecki took over the duty as the head of the Nervous System Histology Laboratory and then the Department of Neuropathology. He held the post continuously until 1998, for 35 years. At the Psychoneurological Institute in Tworki, the histology laboratory was located in the basement in four rooms, but with a separate archive of brains. After the Institute was moved to Warsaw in 1972, the Department of Neuropathology occupied the area of one floor of the main building, where prof. Jerzy Dymecki launched, apart from the laboratory of clin- 
ical neuropathology, also a laboratory for experimental neuropathology, electron microscopy, a laboratory for morphometry and an archive of brains, paraffin blocks and histological preparations. Jerzy Dymecki received a professorship nomination in 1978. He was a supervisor of eight PhD theses, author and coauthor of 115 scientific papers, editor of three Polish books on neuropathology and numerous reports at national and international conferences. The main topics of the Professor's research interests were vascular and neurodegenerative diseases, especially Parkinson's and Alzheimer's diseases. He collaborated with world-renowned neuropathological centres. He continued his special, long-term cooperation with his friend prof. Henryk Wiśniewski, director of the Institute for Basic Research in Developmental Disabilities (IBR) in New York. He was awarded the Golden Cross of Merit. Professor Jerzy Dymecki was a man of great personal culture, kindness, and his approving attitude encouraged all employees to individual scientific development. He was very devoted to his family, daughter and grandchildren, for whom he wrote two books entitled "Memoirs of an old doctor, written down for grandchildren and great-grandchildren" part one and part two. He died on 31 August 2020, in the year of the COVID-19 pandemic, at the age of 94.

Teresa Wierzba-Bobrowicz 